Table 2. Change in arterial $\mathrm{CO}_{2}$ tension caused by $\mathrm{O}_{2}$ inhalation (nasal catheter $1 \mathrm{~L} / \mathrm{min}$ ) found on 33 cases with chronic pulmonary emphysema. Figures-in the table represent numbers of cases observed.

\begin{tabular}{l|c|c|c}
\hline \multicolumn{2}{l|}{} & \multicolumn{2}{c}{$\begin{array}{c}\text { Elevation of arterial } \mathrm{CO}_{2} \text { tension } \\
\text { Over 3 Torr than 3 Torr }\end{array}$} \\
\hline $\begin{array}{l}\text { Arterial } \mathrm{CO}_{2} \text { tension } \\
\text { prior to } \mathrm{O}_{2} \text { admin- } \\
\text { istration }\end{array}$ & Over 45 Torr & 10 & 9 \\
\hline \multicolumn{2}{c|}{ Lower than 45 Torr } & 8 & 6 \\
\hline
\end{tabular}

arterial hypoxemia and not every cases with such impediment reveal exaggerated $\mathrm{CO}_{2}$ retension under the treatment of administering $\mathrm{O}_{2}$ of high concentration.

As being described above the acute exacerbation furnishes us with many important clinical and pathophysilological problems with reference to the chronic respiratory failure. Thus in this present symposium the participants focused their discussion on this particular problem of acute exacerbation in chronic respiratory failure.

\section{LITERATURE CITED}

1) Sasamoto $\mathrm{H}$ and Yokoyama $\mathrm{T}$ : Pulmonary insufficiency and respiratory failure. Respiration and Circulation 17: 4, 1969.

2) Yokoyama $\mathrm{T}$ : Chronic respiratory distress. Clinical significance of arterial blood gas abnormalities. Jap J Med 15: 151, 1976.

3) Yokoyama $\mathrm{T}$ and Furukawa $\mathrm{T}$ : Concepts and diagnostic criteria for respiratory failure. Respiration Research 2: 593, 1983.

\title{
2. Risk Factors in Acute Exacerbation and their Influence on the Prognosis of Chronic Respiratory Failure
}

\author{
Yoshinosuke FukUchi, MD \\ Department of Geriatrics, Faculty of Medicine, University of Tokyo, Tokyo, Japan
}

Respiratory failure (REF) is characterized by multifactorial causes, cimplicated clinical profiles and multiorgan involvement. In order to elucidate morbidity, pathophysiology, natural history and prognosis of $\mathrm{RF}$, retrospective study was conducted at this department and affiliated hospital to find 63 cases of various origin. In addition, a nationwide survey was conducted by distributing a questionnaire and asking the result of pertinent clinical as well as laboratory examination. $\mathrm{RF}$ is arbitrarily defined as respiratory disorders of which $\mathrm{PaO}_{2}$ is 60 torr or less or equivalent abnormal state.

Twenty one institutions complied with the request and provided the complete data of $\mathrm{RF}$ on
1093 cases. As the symposium focus at chronic respiratory failure, this report is concerned mainly with chronic REF (CREF) who suffered from respiratory failure at least a month or longer.

As many factors as $\mathbf{2 8 6}$ that are related to acute exacerbation, clinical course and prognosis were selected and fed to a computer. The statistical analysis of these data were made with the SPSS. The result obtained from the patient of both local and nationwide distribution can be summarized as follows.

(1) Incidence of REF was $4.5 \%$ among hospitalized patients, whereas that of CREF was $5.6 \%$ among autopsied cases.

(2) Major underlying disease responsible for 
CREF include tuberculosis and related conditions (43.3\%), chronic obstructive pulmonary disease $(43 \%)$, lung cancer $(6 \%)$, and interstitial pneumonitis (5\%). On average REF was observed in one third after 5 years and in half after 10 years from the onset of those underlying illness.

(3) Acute exacerbation (AE) requiring hospitalization of the CREF were reported 2.5 times on average ( $1-10$ times) during their observation period. AE was not more than 3 times for $77 \%$ of CREF.

(4) Cumulative survival curve obtained with life table method indicated that survival rate was
$62.5 \%$ at 3 years, $42.5 \%$ at 5 years and $34.5 \%$ at 7 years after the onset of REF. The survival rate was $60.7 \%$ after three times, and $44.8 \%$ after five times of A.E. The cause of death was attributable to respiratory disease in $77 \%$ of CREF.

(5) The risk factors that carries poor prognosis for CREF include old age, right heart failure peptic ulcers and abnormal serum electrolytes. Factors that relates to favorable prognosis consist of those with COPD as underlying pathology, those who has longer history before the onset of REF, and those who has higher $\mathrm{PaO}_{2}$ at the time of $\mathrm{AE}$.

\title{
3. The Pulmonary Gas Exchange during the Acute Exacerbation of Chronic Respiratory Failure
}

\author{
Takeo KAWASHIRO, MD \\ Department of Medicine, School of Medicine, Keio University
}

This study was conducted to investigate the impairment of gas exchange in the lungs during acute exacerbation of chronic respiratory failure. Respiratory failure was defined as the respiratory impairment in which arterial $\mathrm{O}_{2}$ tension fell below 60 torr (or the patient shows the equivalent symptoms) while inhaling room air, as agreed by the research committee on respiratory failure of the Ministry of Health and Welfare of Japan. Chronic respiratory failure was defined as respiratory failure lasting for not less than a month. Acute exacerbation of chronic respiratory failure referred to those cases in which a further and rapid deterioration of chronic respiratory failure occurred to a condition which required more intensive treatment, preferably hospitalization.

\section{SUBJECTS AND METHODS}

Thirty-eight patients were studied in this investigation. All of them were inpatients who had been admitted to Keio University Hospital with acute exacerbation of chronic respiratory failure. Arterial blood gas examination was per- formed on all of the subjects while inhaling room air, both during the stable and the acute exacerbation period of their chronic respiratory failure. The clinical diagnoses of the subjects were as follows: chronic pulmonary emphysema (CPE, 11 patients), interstitial pneumonitis and pulmonary fibrosis (FLD, 10 patients), post-thoracoplasty and/or callosity of the pleura and/or deformity of the thorax (thorax group, 10 patients) and others ( 7 patients). The total number of episodes of acute exacerbation experienced by the subjects was 78 .

Right heart catheterization studies were performed on 5 of the 38 patients both during the stable period and during the acute exacerbation period. These studied enabled analysis of the distribution spectra of ventilation-perfursion ratios $\left(\dot{\mathrm{V}}_{\mathrm{A}} / \dot{\mathrm{Q}}_{\mathrm{C}}\right)$ in the lungs and comparison of $\dot{\mathrm{V}}_{\mathrm{A}} / \dot{\mathrm{Q}}_{\mathrm{C}}$ uneven distributions during the acute exacerbation period and the stable period. In the analysis $\mathrm{O}_{2}, \mathrm{CO}_{2}$ and $\mathrm{N}_{2}$ were used as indicator gases, and no diffusion barriers for these indicator gases were assumed. 